\title{
Pseudohyperkalemia in Serum: A New Insight into an Old Phenomenon
}

\author{
Nikolaos Sevastos, MD; George Theodossiades, MD; Athanasios J. Archimandritis, MD, PhD
}

\begin{abstract}
Pseudohyperkalemia, a rise in serum potassium concentration with concurrently normal plasma potassium concentration, is an in vitro phenomenon that was first described 50 years ago. It was originally attributed to the release of potassium from platelets during platelet aggregation and degranulation, and a significant correlation between pseudohyperkalemia and platelet count was established. During the last decade, new data were added to this phenomenon. In particular, pseudohyperkalemia was defined when serum potassium concentration exceeded that of plasma by more than $0.4 \mathrm{mmol} / \mathrm{L}$ provided that samples are collected under strict techniques, remain at room temperature and are tested within I hour from blood specimen collection. Moreover, it is positively correlated to (I) thrombocytosis due to the release of potassium from platelet granules during coagulation, (2) erythrocytosis due to the dilution of the released potassium in smaller volumes of serum, and (3) the presence of activated platelets, which have the capability of aggregation at a higher speed and release more potassium during degranulation. However, pseudohyperkalemia may be "masked" when in a state of hypokalemia because potassium moves back into the intracellular space in vitro, and the phenomenon is ameliorated or even not detected.
\end{abstract}

Keywords: Erythrocytosis; Leucocytosis; Plasma potassium; Pseudohyperkalemia; Serum potassium; Thrombocytosis

$\mathrm{H}$

yperkalemia, as measured by the marked elevation of serum potassium levels, usually occurs in renal failure, adrenal insufficiency and massive tissue breakdown such as in trauma, rhabdomyolysis, marked hemolysis and in the tumor lysis syndrome. This condition may produce alterations in cardiac excitability with significant changes in the electrocardiogram, including the induction of cardiac arrhythmias, which can cause sudden death. In such cases, an aggressive therapeutic approach is necessary.

The phenomenon of pseudohyperkalemia was first reported by Hartmann and Mellinkoff ${ }^{1}$ in 1955 as a marked elevation of serum potassium levels in the absence of clinical evidence of electrolyte imbalance. No toxic manifestation of hyperkalemia is present and no emergency therapy is required because the elevation of serum potassium concentration does not reflect the level of plasma potassium in vivo. Hartmann and his colleagues ${ }^{1,2}$ concluded that the high potassium in serum is due to leakage from platelets in vitro during the clotting process, and was confirmed in many

Reprint Requests: Nikolaos Sevastos, MD, Second Department of Internal Medicine, Hippokration General Hospital, Vas. Sophias II4, II527 Athens, Greece, Tel: +30 210 7774742, Fax: +30 210 770687I, E-mail: nsevast@med.uoa.gr studies thereafter. ${ }^{3-7}$ However, in 1960 Nilsson et al, ${ }^{8}$ in order to explain some of the observed cases, suggested that potassium could be released from other cellular components and assumed that the red cells might be the source.

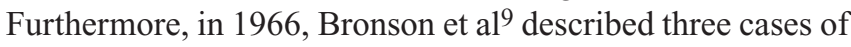
pseudohyperkalemia in chronic myelogenous leukemia in transformation and concluded that white blood cell breakdown could cause the release of potassium during coagulation as well. This observation resulted in confusion concerning which cellular component of blood is responsible and why it is not observed in every case where an increase of this component is present.

In the mid 1980s, new data were added to this phenomenon. In particular, the lag time between blood collection and potassium determination was confined to a maximum of 30 minutes, ${ }^{10,11}$ and a positive correlation between platelet count and serum, ${ }^{11,12}$ but not plasma potassium concentration, was found. ${ }^{10}$

\footnotetext{
Received: December 13, 2006

Ist Revision: May 25, 2007 2nd Revision: September 25, 2007

Accepted: October 10, 2007
}

doi: $10.3121 / \mathrm{cmr} .2008 .739$ 
Table 1. Indexes Dk and Dk100 (mean value and range) in patients with increased one or more of the cellular components of blood and controls.

\begin{tabular}{|c|c|c|}
\hline Clinical settings & Dk (mmol/L) & Dk 100 (mmol/L) \\
\hline Thrombocytosis (n=129) & $0.82(0.01-1.90)^{*}$ & $0.12(0.00-0.28)$ \\
\hline Leucocytosis $(n=29)$ & $0.22(0.01-0.76) \dagger$ & $0.20(0.01-1.80)$ \\
\hline Erythrocytosis ( $\mathrm{n}=95)$ & $0.39(0.02-0.73) \ddagger$ & $0.15(0.01-0.37)$ \\
\hline Mixed type disorders $(n=182)$ & $0.82(0.00-2.61) \delta$ & $0.15(0.00-9.14)$ \\
\hline Controls $(n=30)$ & $0.27(0.02-0.42) \emptyset$ & $0.11(0.02-0.21)$ \\
\hline \multicolumn{3}{|c|}{ 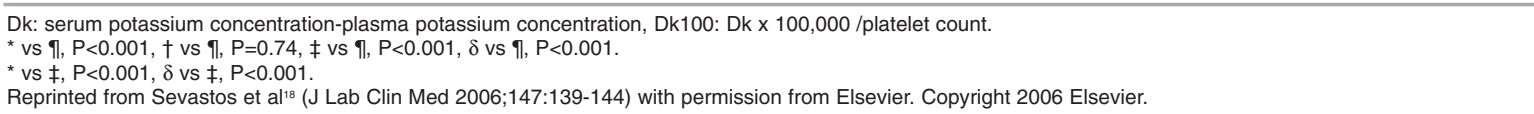 } \\
\hline
\end{tabular}

\section{Recent Advances}

In 1997, Singh et al $^{13}$ suggested that pseudohyperkalemia should only be considered when the serum potassium level exceeds that of plasma by $0.4 \mathrm{mmol} / \mathrm{L}$, and in 2002, Fukasawa et al ${ }^{14}$ showed that normal counts of activated platelets might also be the cause. This finding was confirmed in later studies, ${ }^{15,16}$ where pseudohyperkalemia was attributed to the presence of activated platelets and observed in a few patients admitted to intensive care units with normal platelet counts.

Based on the above-mentioned background, we recently tried to extensively investigate the phenomenon of pseudohyperkalemia in the various conditions where it had been previously described. ${ }^{17,18}$ The difference between serum and plasma potassium concentration (Dk) and a new index Dk100 (Dk x 100,000/platelets), which indicates what Dk corresponds to in $100,000 / \mathrm{mm}^{3}$ of platelets, were estimated in patients with an increase in one or more of the cellular components of blood using standardized methods of blood collection, storage and testing. The index Dk100 was used because Dk values were substantially lower than expected in patients with extremely high platelet counts. Dk100 appears to be a relative estimate of the platelet contribution to pseudohyperkalemia and an attempt to normalize this contribution.

The median Dk was found to be significantly higher in the groups with platelet, erythrocyte or with mixed-type disorders than in controls. On the contrary, no significant difference was observed between controls and the group with white blood cell disorders (table 1), a finding that was in contrast to what had been previously described.9,19-22 This may be due to the fact that in other studies no strict times-tospecimen processing were followed, and delays could have affected the results.

Moreover, a new finding that had not been previously described was the contribution of the red blood cells to the development of pseudohyperkalemia. In patients with isolated erythrocytosis, such as chronic obstructive pulmonary disease and congestive cyanotic heart disease, median Dk values were found to be higher than in controls, but lower than in those with thrombocytosis or mixed-type disorders (table 1) and, in addition, Dk was inversely correlated with hematocrit. Thus, it is reasonable to speculate that, in patients with erythrocytosis, the potassium load that exits platelets during the clotting process may be diluted in a significantly smaller volume of serum, which results in increased potassium concentration. However, in isolated erythrocytosis Dk never exceeded the value of $0.70 \mathrm{mmol} / \mathrm{L}$ that was identified as a significant independent predictor of polycythemia vera. ${ }^{17}$

Lastly and most importantly, Dk values were found to be significantly correlated to platelet count. In particular, among patients with isolated thrombocytosis or with mixed type disorders, Dk was usually high, ranging between 0.40 and $2.61 \mathrm{mmol} / \mathrm{L}$, as had been previously reported (table 1$).{ }^{10,23}$ However, there were some cases of thrombocytosis with $\mathrm{Dk} \leq 0.40 \mathrm{mmol} / \mathrm{L}$ that were correlated to severe hypokalemia. In particular, in a study of serum-plasma differences in a patient with a myeloproliferative disease and

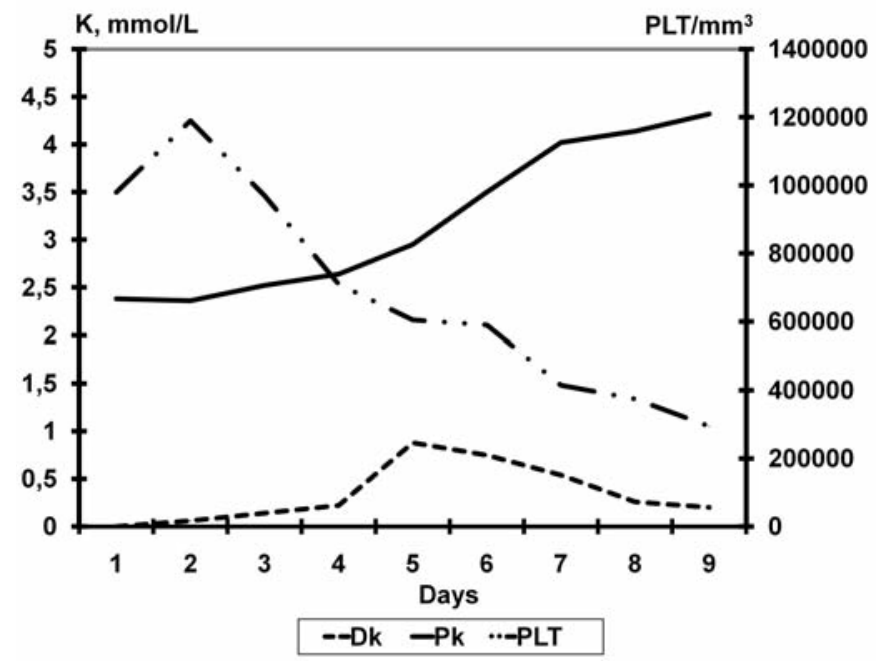

Figure 1. Changes in plasma potassium concentration (Pk) and serum potassium concentration minus plasma potassium concentration (Dk) in relation to platelet count (PLT) in a patient with thrombocytosis due to myeloproliferative disorder and severe hypokalemia due to excessive use of furosemide. The patient was treated with hydroxyurea and potassium supplements and a sudden increase of Dk was observed 5 days later, when $\mathrm{Pk}$ levels reached to $3 \mathrm{mmol} / \mathrm{L}$, despite the decrease of platelet count to $500,000 / \mathrm{mm} 3$. Reprinted from Sevastos et $\mathrm{al}^{18}$ (J Lab Clin Med 2006;147:139-144) with permission from Elsevier. Copyright 2006 Elsevier. 
thrombocytosis, who had severe hypokalemia due to excessive use of furosemide, Dk was zero in repeated occasions. The patient was treated with hydroxyurea and potassium supplements and a sudden increase of Dk was observed 5 days later when normal potassium balance was restored despite the decrease of platelet count (figure 1). ${ }^{18}$ This case study nicely demonstrates the value of using plasma rather than serum potassium concentration as a clinical measure.

In conclusion, pseudohyperkalemia in serum seems to be the result of two independent and sequential mechanisms: (1) degranulation of platelets, which offers a potassium load to the surrounding serum at the time of clot formation in vitro, and (2) transfer of a part of this potassium load back into blood cells in order to maintain electrolyte and osmotic homeostasis. The net result is that a significant amount of potassium remains in serum giving rise to the phenomenon of pseudohyperkalemia.

\section{References}

1. Hartmann RC, Mellinkoff SM. Relationship of platelets to serum potassium concentration. J Clin Invest 1955;34:938.

2. Hartmann RC, Auditore JV, Jackson DP. Studies on thrombocytosis. I. Hyperkalemia due to release of potassium from platelets during coagulation. J Clin Invest 1958;37: 699-707.

3. Frick PG. Pseudohyperkalemia in thrombocytosis. Schweiz Med Wochenschr 1960;90:433-435

4. Myerson RM, Frumin AM. Hyperkalemia associated with the myeloproliferative disorder. Arch Intern Med 1960; 106:479-482.

5. Ingram RH Jr, Seki M. Pseudohyperkalemia with thrombocytosis. N Engl J Med 1962;267:895-900.

6. Wills MR, Fraser ID. Spurious hyperkalaemia. J Clin Pathol 1964;17:649-650.

7. Whitefield JB. Spurious hyperkalaemia and hyponatraemia in a patient with thrombocythaemia. J Clin Path 1966;19:496-497.

8. Nilsson IM, Skanse B, Bjorkman SE, Serin F. Platelet function in thrombocythemia. The effect of platelets and serotonin on serum potassium and bilirubin. Acta Med Scand 1960;167:353-368.

9. Bronson WR, DeVita VT, Carbone PP, Cotlove E. Pseudohyperkalemia due to release of potassium from white blood cells during clotting. N Engl J Med 1966;274:369-375.

10. Modder B, Meuthen I. Pseudohyperkalemia in the serum in reactive thrombocytosis and thrombocythemia. Dtsch Med Wochenschr 1986;111:329-332.

11. Wulkan RW, Michiels JJ. Pseudohyperkalaemia in thrombocythaemia. J Clin Chem Clin Biochem 1990; 28:489-491.

12. Graber M, Subramani K, Corish D, Schwab A. Thrombocytosis elevates serum potassium. Am J Kidney Dis 1988; 12:116-120.

13. Singh PJ, Zawada ET, Santella RN. A case of 'reverse' pseudohyperkalemia. Miner Electrolyte Metab 1997; 23:58-61.

14. Fukasawa H, Furuya R, Kato A, Yonemura K, Fujigaki Y, Yamamoto T, Hishida A. Pseudohyperkalemia occurring in a patient with chronic renal failure and polycythemia vera without severe leukocytosis or thrombocytosis. Clin Nephrol 2002;58:451-454.
15. Tsolakidis GF, Drivakou A, Anthopoulos G, Sevastos N. Serum and plasma potassium levels in ICU patients. Intensive Care Medicine 2003;29:S165.

16. Tsolakidis GF, Fourka S, Anthopoulos G, Kaninis C, Sevastos N. Pseudohyperkalemia during the onset of clinical illness. Critical Care 2004;8:S129.

17. Sevastos N, Theodossiades G, Savvas SP, Tsilidis K, Efstathiou $\mathrm{S}$, Archimandritis AJ. Pseudohyperkalemia in patients with increased cellular components of blood. Am J Med Sci 2006;331:17-21.

18. Sevastos N, Theodossiades G, Efstathiou S, Papatheodoridis GV, Manesis E, Archimandritis AJ. Pseudohyperkalemia in serum: the phenomenon and its clinical magnitude. J Lab Clin Med 2006;147:139-144.

19. Chumbley LC. Pseudohyperkalemia in acute myelocytic leukemia. JAMA 1970;211:1007-1009.

20. Bellevue R, Dosik H, Spergel G, Gussoff BD. Pseudohyperkalemia and extreme leukocytosis. J Lab Clin Med 1975;85:660-664.

21. Ho-Yen DO, Pennington CR. Pseudohyperkalaemia and infectious mononucleosis. Postgrad Med J 1980;56:435-436.

22. Colussi G, Cipriani D. Pseudohyperkalemia in extreme leukocytosis. Am J Nephrol 1995;15:450-452.

23. Ralston SH, Lough M, Sturrock RD. Rheumatoid arthritis: an unrecognised cause of pseudohyperkalaemia. BMJ 1988;297:523-524.

\section{Author Affiliations}

Nikolaos Sevastos, MD

Second Department of Internal Medicine

National University of Athens Medical School

Athens, Greece

George Theodossiades, MD

First Regional Transfusion Center

Hippokration General Hospital

Athens, Greece

Athanasios J. Archimandritis, MD, PhD

Second Department of Internal Medicine

National University of Athens Medical School

Athens, Greece 